\title{
Comparison of different biological treatment scenarios for the organic fraction of municipal solid waste
}

\author{
L. Lombardi · E. A. Carnevale $\cdot$ A. Corti
}

Received: 7 January 2013/Revised: 26 June 2013/Accepted: 2 November 2013/Published online: 4 December 2013

(C) Islamic Azad University (IAU) 2013

\begin{abstract}
The possibility of applying anaerobic digestion (AD) process of the source-selected organic fraction (SSOF) of municipal solid waste in the south of Tuscany (IT) territory was proposed and evaluated. With respect to a reference scenario, in which the overall amount of SS-OF and garden waste-expected in 2013-is addressed to aerobic composting process, three alternative scenarios were proposed, modeled, and compared by life cycle assessment (LCA). The first one is based on realizing six $\mathrm{AD}$ plants upstream of each already existing aerobic plant. The second one is based on realizing only three centralized anaerobic plants. The third alternative is based on codigestion of a part of the SS-OF with sludge from waste water treatment plants in existing sludge $\mathrm{AD}$ plants; the remaining part of SS-OF is processed in devoted AD plants upstream of each already existing aerobic plant. LCA results show that $\mathrm{AD}$ application is always favorable with respect to the reference scenario in which organic wastes are aerobically processed. AD allows for net production of thermal and electric energy, generating negative impacts due to avoided emissions and avoided resource consumptions. Among the compared alternatives of AD application, the scenario based on decentralized plants (one anaerobic plant upstream of each existing aerobic plant) resulted to be most favorable, collecting the best value for almost all the considered environmental indicators.
\end{abstract}

L. Lombardi $(\bowtie) \cdot$ E. A. Carnevale

Department of Industrial Engineering, University of Florence,

via Santa Marta 3, 50139 Florence, Italy

e-mail: lidia.lombardi@unifi.it

A. Corti

Department of Information Engineering and Mathematics, University of Siena, via Roma 56, 53100 Siena, Italy
Keywords Biodegradable waste - Anaerobic digestion . Co-digestion $\cdot$ Life cycle assessment $\cdot$ Compost

\section{Introduction}

The source-selected organic fraction (SS-OF) of municipal solid waste (MSW) is a highly biodegradable material; therefore, the most suitable alternative ways of management are biological processes, such as composting and anaerobic digestion (AD). Today, the installed capacity of AD is fast increasing. De Baere and Mattheeuws (2011) expected in Europe an installed capacity by the end of 2010 of about 6,000,000 tons per year divided over 200 plants in 17 countries.

This study was originated in the frame of the collaboration with the authority of MSW management Ambito Territoriale Ottimale Toscana Sud (ATO Toscana Sud), within a project co-financed by the Tuscany Region. The aim of the project is to evaluate the potential environmental benefits, which may arise from the application of $\mathrm{AD}$ of SS-OF of MSW with reference to the territory of competence of the ATO Toscana Sud, which includes the provinces of Arezzo, Siena, and Grosseto, possibly integrating the AD process with the existing plants. Such integration strategy was interpreted according to two technological possibilities: wet anaerobic process (Mata-Alvarez 2003) in plants devoted to SS-OF treatment, realized upstream of the existing aerobic biostabilization plants, in order to exploit such plants for post-composting process of the digestate; and SS-OF co-digestion in existing anaerobic digesters for waste water treatment plant (WWTP) sludge, in order to exploit existing digestion capacity.

Anaerobic co-digestion (CO-AD) of SS-OF and WWTP sludge appears to be an interesting solution to increase the 
biogas production of poorly performing under-loaded digesters of sewer sludge (Mata-Alvarez et al. 2000).

About 36,000 WWTPs that adopt the anaerobic stabilization of sewage or waste-activated sludge are operating in the EU (Bolzonella et al. 2006).

Co-digestion of the organic fraction of MSW together with WWTP sludge is beneficial due to a number of substrate characteristics of both waste types that are complementary in their combination (Mata-Alvarez 2003). The addition of high solids concentration of organic fraction of MSW to sludge digester operated with sludge having a low solid content will be possible even in rather high concentrations (Mata-Alvarez 2003). The higher concentration of macro- and micronutrients in the sludge solids will compensate the lack of nutrients in the organic fraction of MSW (Mata-Alvarez 2003).

Several investigations in the field of co-digestion of organic fraction of MSW have been made. However, codigestion in solid waste (SW) treatment in Europe is not so much common, as barely $7 \%$ of capacity is provided by plants using co-digestion (De Baere 2006).

In order to proceed with the analysis, the studied territory was characterized in terms of SS-OF production with reference to future years and treatment capacity of the existing —and planned-aerobic biostabilization plants (six plants). Also, after a wide survey in the territory of interest, three WWTPs, equipped with $\mathrm{AD}$ and suitable for accepting SS-OF as co-substrate, were selected.

Concerning the devoted wet anaerobic plants, two possibilities were considered: six small anaerobic digesters spread over the territory upstream of the existing aerobic biostabilization plants and three centralized anaerobic digesters.

Different management scenarios were, hence, assumed and characterized in terms of mass and energy inventory and compared performing a life cycle assessment (LCA) (ISO 14040-44 2006). The LCA methodology provides an excellent framework for evaluating MSW management strategies. Many of its applications in this field are focused on the use of the LCA methodology as a decision support tool in the selection of the best MSW treatment (Zaman 2010, 2013) and management strategy (from an environmental point of view) in a wide range of countries (Cleary 2009; Tunesi 2011; Bovea et al. 2010; Bernstad and la Cour 2011; Thanh and Matsui 2012; Antonopoulos et al. 2013).

For this reason, in this study, LCA was applied to evaluate different treatment possibilities for the SS-OF produced in the south of Tuscany (IT), in reference to the amounts expected for the year 2013. The main originality issue of this work is related to the rather detailed application of LCA, based on modeling as accurately as possible the considered processes, in reference to devoted data collected and modeled for the specific cases. Moreover, while the comparison between aerobic and anaerobic biological treatments is quite common, the inclusion of codigestion in LCA is rather novel. Further, the study is aimed at adhering as much as possible to the existing situation in the reference territory, assuming as constraints the available plants-and hence the logistic of transport-and their effective capacity of processing waste.

In the following, the different steps of the study will be reported according to the LCA's phases (ISO 14040-44 2006).

This research was carried out from the end of 2009 to 2011, at the Industrial Engineering Department of the University of Florence, Italy.

\section{Materials and methods}

LCA: goal and scope definition

The goal definition is the first phase of the LCA in which the purpose of the study is described. It identifies and defines the object of the assessment.

The purpose of this LCA study is to compare the environmental impacts and resource consumption of four different management scenarios for the SS-OF collected in the south Tuscany territory: aerobic composting in already existing plants, which represents the present situation; $A D$ realizing an anaerobic plant upstream of each already existing aerobic plant; $\mathrm{AD}$ realizing three centralized anaerobic plants; co-digestion of a part ${ }^{1}$ of the SS-OF with sludge from WWTP in existing sludge AD plants, while the remaining SS-OF is processed in decentralized anaerobic plant realized upstream of the existing aerobic ones.

The primary service provided by the studied systems is the biological degradation of the SS-OF in order to avoid, according to a correct waste management system, undesired degradation phenomena in landfill.

The functional unit is defined as the management and the treatment of the whole amount of SS-OF produced in the south of Tuscany, with reference to the quantity expected in the year 2013.

For each of the studied scenario, the analyzed system boundary starts with the arrival of the SS-OF to the first treatment plant (i.e., separate collection and transport impacts are not included), the biological processes (anaerobic and/or aerobic), energy production, residual water treatment, transport of scraps to landfill, and eventual transport of SS-OF or digestate among plants. In particular in Scenarios 1 and 2, no transport is considered for the SS-

\footnotetext{
1 The estimated capacity of co-digestion is not enough to process all the SS-OF amount.
} 
OF that enters the system as input to the local aerobic/ anaerobic plant, and it is processed on site. In Scenario 3, the SS-OF transport to one centralized anaerobic plant located in each of the three provinces of the considered territory is included. In Scenario 4, the SS-OF transport to WWTP digester and the digestate transport back to the composting plant are considered. More details on amount and transport distance are given in the scenario definition paragraphs.

The different types of scraps that originate from the waste processes (scraps from AD pretreatment, scraps from compost postprocessing, and sludge from the treatment of wastewater/leachate originated in $\mathrm{AD}$ and composting processes) are assumed to be sent to landfill. The related impacts are considered only in terms of the amount of solids disposed to landfill, disregarding the type and composition, contributing to the solid waste indicator, as it is defined in the result and discussion paragraph.

For these scraps, the transportation to landfill was considered, assuming an average distance of $50 \mathrm{~km}$.

The avoided effects potentially deriving from substitution of conventional soil correctives with produced compost in agriculture (Boldrin et al. 2011a) were considered, in terms of the avoided contributions to global warming potential.

According to Manfredi and Christensen (2009), it was assumed that emission of biogenic $\mathrm{CO}_{2}$-i.e., the $\mathrm{CO}_{2}$ coming from aerobic biostabilization or the $\mathrm{CO}_{2}$ contained/ originated in/from the $\mathrm{AD}$ gas-is neutral to global warming because the $\mathrm{CO}_{2}$ originates from organic matter generated by an equivalent biological uptake during plant growth (IPCC 2006).

\section{LCA: inventory}

In this phase, all the environmental inputs and outputs occurring in the life cycle of the systems previously defined are inventoried to perform a quantitative description of all flows of materials and energy across the system boundary either into or out of the system itself.

\section{Source-selected organic fraction of MSW and WWTP sludge}

The overall amount of the SS-OF expected to be produced in 2013 in the south Tuscany is about 105,399 t/year (ATO Toscana Sud 2008). Table 1 reports the amount of SS-OF in reference to each composting plant where the collected amount should be processed, according to the authority planning and decisions (ATO Toscana Sud 2008). Also, the amount of the separately collected garden waste $(\mathrm{GW})$ which is expected to be about 12,302 t/year in 2013-is reported, according to the destination plants. For each
Table 1 Amount of SS-OF and GW expected in south Tuscany in 2013, reported according to the planned destination plant, and amount of sludge to AD in the selected WWTP

\begin{tabular}{|c|c|c|c|c|c|}
\hline \multicolumn{2}{|c|}{$\begin{array}{l}\text { Aerobic } \\
\text { biostabilization plant }\end{array}$} & $\begin{array}{l}\text { SS-OF } \\
{[\mathrm{t}]}\end{array}$ & $\begin{array}{l}\mathrm{GW} \\
{[\mathrm{t}]}\end{array}$ & Type & $\begin{array}{l}\text { Capacity } \\
\text { (t/a) }\end{array}$ \\
\hline \multicolumn{2}{|l|}{ A } & 9,430 & 1,850 & Composting & 15,000 \\
\hline \multicolumn{2}{|l|}{ B } & 20,854 & 1,889 & Composting & 35,000 \\
\hline \multicolumn{2}{|l|}{$\mathrm{C}$} & 27,648 & 2,500 & Composting & 24,000 \\
\hline \multicolumn{2}{|l|}{$\mathrm{D}$} & 10,002 & 1,724 & Composting & 13,000 \\
\hline \multicolumn{2}{|l|}{$\mathrm{E}$} & 22,096 & 2,792 & Composting & 27,500 \\
\hline \multicolumn{2}{|l|}{$\mathrm{F}$} & 15,369 & 1,547 & Composting & 9,800 \\
\hline \multicolumn{2}{|l|}{ Total amount } & 105,399 & 12,302 & - & - \\
\hline WWTP & \multicolumn{3}{|c|}{ Input WW $\left[\mathrm{m}^{3} 10^{6} /\right.$ year $]$} & \multicolumn{2}{|c|}{ Sludge to AD [t/year] } \\
\hline WWTP1 & \multicolumn{3}{|l|}{5} & \multicolumn{2}{|l|}{67,388} \\
\hline WWTP2 & \multicolumn{3}{|l|}{2.763} & \multicolumn{2}{|l|}{37,234} \\
\hline WWTP3 & \multicolumn{3}{|l|}{2.358} & \multicolumn{2}{|l|}{31,763} \\
\hline
\end{tabular}

plant, the maximum treatment capacity is also reported. Even if the overall capacity exceeds the overall amount of SS-OF and GW, in the case of plant $\mathrm{C}$ and $\mathrm{F}$ the treatment capacity would not be sufficient.

After a wide survey in the territory of interest, the WWTPs, equipped with AD and suitable for accepting SSOF as co-substrate, were selected and reported in Table 1, together with the amount of input waste water, in reference to year 2007 (SINTAI 2011). The amounts of produced sludge per each WWTP_-which are subsequently addressed to $\mathrm{AD}$-were estimated, according to specific sludge production factors retrieved from the literature (Metcalf and Eddy 1991; Vesilind 2003), and reported in Table 1.

Concerning the characteristics of the SS-OF, material composition analyses were performed on samples coming from road-container collection system in two municipalities in the territory of south Tuscany. Table 2 reports the results of the material analysis and the assumed total solid (TS) and total volatile solid (TVS) contents for each material (Miller and Clesceri 2003), used to estimate the average TS and TVS contents of the SS-OF, which are reported in the last raw of Table 2 .

Scenario 1 is built around the aerobic composting of the estimated amount of SS-OF and GW for 2013, in the six already existing plants. It represents the existing situation in term of plants, and it is described by the data reported in Table 1. As already noted, plants $\mathrm{C}$ and $\mathrm{F}$ would not be able to process the estimated amount of waste. So, for the real application of Scenario 1, an increment in the two plants capacity should be considered. The composting process was modeled in the same way for the six plants. The amount of exiting TS was calculated, starting from the characterization values - in terms of TS and TVS-of the SS-OF and GW reported in Table 2 and applying a TVS 
Table 2 Measured material composition of SS-OF and assumed TS and TVS contents

\begin{tabular}{llll}
\hline $\begin{array}{l}\text { Material } \\
\text { composition of SS-OF }\end{array}$ & $\begin{array}{l}\text { w/w } \\
{[\%]}\end{array}$ & $\begin{array}{l}\text { TS } \\
{[\%]}\end{array}$ & $\begin{array}{l}\text { TVS } \\
{[\% \text { of TS }]}\end{array}$ \\
\hline Kitchen waste & 87.39 & 30.00 & 80.00 \\
Garden waste & 1.95 & 40.00 & 85.00 \\
Paper and cardboard & 2.25 & 50.00 & 67.34 \\
Inert & 1.61 & 98.00 & - \\
Metals & 0.13 & 88.00 & - \\
Hazardous & 0.09 & 80.00 & 79.70 \\
Plastics & 3.91 & 95.00 & 79.70 \\
Flexible polylaminate packaging & 0.09 & 95.00 & 79.70 \\
Glass & 0.00 & 98.00 & - \\
Wood & 2.26 & 80.00 & 80.92 \\
Electronic waste & 0.08 & 98.00 & - \\
Diapers & 0.24 & 50.00 & 66.00 \\
SS-OF (average) & - & 35.69 & 74.70 \\
\hline
\end{tabular}

degradation efficiency value of $40 \%$ (ATO Toscana Sud. Personal communication), somewhat higher than values of about 30-33 \% found in (Chang et al. 2006; Kumar et al. 2010), but less optimistic than values (67-73\%) assumed in (Boldrin et al. 2011b). The overall amount of compost was estimated assuming that the TS content of compost is $45 \%$ (ANPA and ONR 2002).

One of the main problems associated with the treatment of organic wastes in composting facilities is the management and treatment of leachates, which present a high organic load and cannot be stored in the plant (Trujillo et al. 2006). In open-air composting plants, a leachate may be formed at certain times of the year when, following periods of wet weather, the windrow can exceed its drainable limit leading to seepage from the base. In closed environment, leachate can also be generated by highmoisture content wastes (such as fruit and vegetables) as it decomposes (Tyrrel et al. 2008). For the above reasons, and also because leachate production from composting process was reported by the companies managing composting plants in the territory of interest, the production of leachate from composting was considered according to a specific value of $0.4 \mathrm{~m}^{3} / \mathrm{t}$ compost (ATO Toscana Sud. Personal communication) and, subsequently, its treatment was included in the analyzed system, according to the simplified method reported in the paragraph "Wastewater/ leachate treatment."

Consumptions of electric energy (EE) for composting process were considered according to a specific value of $21.5 \mathrm{kWh} / \mathrm{t}$ (ANPA and ONR 2002).

The output from the aerobic biostabilization is postprocessed in order to separate metals, plastics, flexible polylaminate packaging, electronic waste, inert, and glass producing the process scraps. The scraps represent about $9 \%$ of the biostabilization output and are assumed to be transported to landfill (average distance $50 \mathrm{~km}$ ) and landfilled. Also, the wood parts are separated and recirculated to the process inlet (about $1.3 \%$ of biostabilization output).

It is assumed that the produced compost is used in agriculture. As a matter of fact, compost use may generate avoided effects as it may substitute other soil conditioners (i.e., chemical fertilizer, manure, or composted agricultural scraps) generating material and energy preservation, so impact saving.

The main specific benefits obtainable from compost use are as follows: carbon storage in the soil by the compost, avoidance of fossil emissions from the peat substitution, and nitrogen content addiction (Favoino and Hogg 2008; Hermann et al. 2011).

In this analysis, according to Hermann et al. (2011), it was considered that compost can substitute peat and straw with reference to specific substitution factors, which are $0.79 \mathrm{~kg}$ of peat per $\mathrm{kg}$ of compost and $0.73 \mathrm{~kg}$ of straw per $\mathrm{kg}$ of compost. These factors take into account the carbon content and its contribution to humus formation, which allow estimating the long-term carbon sequestration (Hermann et al. 2011).

According to Hermann et al. (2011), compost from industrial composting replaces peat and straw at a ratio of 1:3 based on industrial compost use in the UK, Germany, the Netherlands, and Switzerland.

Combining these information it is possible to calculate overall substitution factors for peat $(0.186 \mathrm{~kg}$ of peat per $\mathrm{kg}$ of compost) and straw (0.56 kg of straw per $\mathrm{kg}$ of compost) by industrial compost. Since $\mathrm{CO}_{2}$ direct emissions of both compost and straw are of biogenic origin, and so neutral (Hermann et al. 2011; Boldrin et al. 2010), the use of compost on land could be considered as a saving of fossil $\mathrm{CO}_{2}$ generated from peat substitution, being the specific $\mathrm{CO}_{2}$ emission from peat equal to $1.07 \mathrm{~kg} \mathrm{CO}$ per $\mathrm{kg}$ of peat (Hermann et al. 2011). Combining the overall substitution factor for peat $(0.186 \mathrm{~kg}$ of peat per $\mathrm{kg}$ of compost) and the specific $\mathrm{CO}_{2}$ emission from peat use on the land, the specific $\mathrm{CO}_{2}$ emission was avoided by the use of compost on land results equal to $0.199 \mathrm{~kg} \mathrm{CO} 2$ per $\mathrm{kg}$ of compost.

The inventory for Scenario 1 is summarized in Table 3, including also the consumptions and the sludge production from the leachate treatment process, according to the assumptions reported in the paragraph "Wastewater/ leachate treatment."

Wastewater/leachate treatment

Leachate originated from a composting process-but also wastewater originated from $\mathrm{AD}$ and co-digestion 
Table 3 Inventory table for Scenarios 1-4

\begin{tabular}{|c|c|c|c|c|c|}
\hline \multirow[t]{2}{*}{ Input } & \multirow{2}{*}{$\begin{array}{l}\text { Scenario } \\
1\end{array}$} & \multirow[t]{2}{*}{ Scenario 2} & \multirow[t]{2}{*}{ Scenario 3} & \multicolumn{2}{|l|}{ Scenario 4} \\
\hline & & & & DA & Co-DA \\
\hline SS-OF [t/year] & 105,399 & 105,399 & 105,399 & 85,202 & 20,197 \\
\hline GW [t/year] & 12,302 & 12,302 & 12,302 & 12,302 & - \\
\hline Sludge [t/year] & - & - & - & - & 136,385 \\
\hline Water [t/year] & - & 53,372 & 53,401 & 43,193 & - \\
\hline Methanol consumption [t/year] & 15 & 53 & 53 & 45 & 79 \\
\hline Flocculants [t/year] & - & 87 & 87 & 70 & - \\
\hline $\mathrm{EE}$ for $\mathrm{AD}$ pretreatments $[\mathrm{kWh} /$ year] & - & $6,395,148$ & $6,395,148$ & $5,169,697$ & $2,499,540$ \\
\hline EE for composting [kWh/year] & $2,530,572$ & $1,520,068$ & $1,520,124$ & $1,580,496$ & - \\
\hline EE for wastewater treatment $[\mathrm{kWh} /$ year $]$ & 92,906 & 318,773 & 318,813 & 269,809 & 477,583 \\
\hline EE total consumption [kWh/year] & $2,623,478$ & $8,233,988$ & $8,234,085$ & $7,020,003$ & $2,977,124$ \\
\hline ET for AD [kWh/year] & - & $12,187,957$ & $12,187,957$ & $11,203,467$ & $6,632,928$ \\
\hline Fuel [t/year] & 8 & 16 & 64 & 19 & 32 \\
\hline \multicolumn{6}{|l|}{ Output } \\
\hline Scraps [t/year] & 6,136 & 11,153 & 11,153 & 9,016 & 2,547 \\
\hline $\begin{array}{l}\text { Sludge from wastewater treatment [ } \mathrm{t} \text { of } \\
\text { dry matter/y] }\end{array}$ & 127 & 436 & 436 & 369 & 654 \\
\hline Compost [t/year] & 57,844 & 37,443 & 37,445 & 38,880 & - \\
\hline Gross EE production [kWh/year] & - & $24,569,284$ & $24,569,995$ & $19,862,490$ & $4,864,703$ \\
\hline Gross ET production [kWh/year] & - & $37,204,915$ & $37,205,993$ & $30,077,485$ & $7,366,550$ \\
\hline Net EE production [kWh/year] & - & $16,335,295$ & $16,451,084$ & $12,883,779$ & $1,887,579$ \\
\hline Net ET production [kWh/year] & - & $25,016,958$ & $25,018,036$ & $18,874,018$ & 733,622 \\
\hline NOx emission to air [kg/year] & - & 29,449 & 29,450 & 23,808 & 5,831 \\
\hline $\mathrm{PM}$ emission to air $[\mathrm{kg} /$ year $]$ & - & 5,669 & 5,669 & 4,583 & 1,122 \\
\hline $\mathrm{CO}$ emission to air $[\mathrm{kg} / \mathrm{year}]$ & - & 55,218 & 55,219 & 44,639 & 10,933 \\
\hline \multicolumn{6}{|l|}{ Emissions from transport } \\
\hline $\mathrm{CO}$ emission to air [kg/year] & 52 & 102 & 496 & 123 & 202 \\
\hline VOC emission to air $[\mathrm{kg} /$ year $]$ & 10 & 20 & 98 & 24 & 40 \\
\hline $\mathrm{CH} 4$ emission to air $[\mathrm{kg} /$ year $]$ & 4 & 7 & 33 & 8 & 14 \\
\hline NMVOC emission to air [kg/year] & 7 & 13 & 65 & 16 & 26 \\
\hline NOx emission to air $[\mathrm{kg} /$ year $]$ & 182 & 354 & 1,726 & 430 & 705 \\
\hline PM emission to air $[\mathrm{kg} /$ year $]$ & 5 & 9 & 43 & 11 & 18 \\
\hline SOx emission to air $[\mathrm{kg} /$ year $]$ & 5 & 9 & 46 & 12 & 19 \\
\hline $\mathrm{CO}_{2}$ emission to air $[\mathrm{kg} /$ year $]$ & 27,423 & 53,234 & 259,696 & 64,612 & 105,990 \\
\hline
\end{tabular}

treatments as explained in the following paragraphsrequires further treatment prior to discharge in a water receptor body. Activated sludge-based treatment was considered, estimating the electric consumptions for aeration, the sludge production, and the methanol consumption for denitrification, according to a simplified calculation procedure deduced from the literature (Orhon and Artan 1994; Sedlak 1991). In particular, starting from an assumed COD and ammonium content of the wastewater, the oxygen demand was estimated $\left(4,21 \mathrm{kgO}_{2} / \mathrm{m}^{3}\right)$; then, considering a specific consumption of $0,5 \mathrm{kWh} / \mathrm{kgO}_{2}$ and knowing that aeration consumption is about $60 \%$ of total electricity consumption, the specific total EE consumption was estimated $\left(3,50 \mathrm{kWh} / \mathrm{m}^{3}\right)$. The methanol consumption $\left(0,58 \mathrm{~kg} / \mathrm{m}^{3}\right)$ for denitrification was estimated calculating the required additional carbon, with respect to available COD. Finally, the sludge production was estimated by means of mass balance $\left(4,79 \mathrm{kgTS} / \mathrm{m}^{3}\right)$.

\section{Scenario 2}

Scenario 2 is built around the hypothesis of realizing an AD plant, for the SS-OF, upstream of each existing aerobic composting plant. The produced digestate is aerobically biostabilized, together with the locally available $\mathrm{GW}$, in each existing aerobic plant. The use of a wet AD process (8.5\% TS content), equipped with an upstream pretreatment based on a pulper, for the SS-OF was assumed and 
modeled. According to Bozano Gandolfi (2008), the upstream-pulper-based process is able to remove from the SS-OF the undesired materials separating a light fraction, in which plastics, flexible polylaminate packaging, wood, and diapers are collected (about $6.50 \%$ of the entering SS$\mathrm{OF})$, and a heavy fraction, in which paper and cardboard, glass, metals, and hazardous waste are collected (about $2.47 \%$ of the entering SS-OF). Finally, the pulped material is screened in a screen with $10-\mathrm{mm}$ holes, removing the inert present in the initial composition $(1.61 \%$ of the entering SS-OF). Scraps from pretreatment process are assumed to be transported to landfill (average distance $50 \mathrm{~km}$ ) and landfilled. The cleaned waste suspension that subsequently gets into the biological treatment is therefore characterized by a high percentage of digestible organic substance. Calculating its TS and TVS content, and assuming a value of TVS degradation efficiency of $54 \%$ and biogas volumetric composition equal to $\mathrm{H}_{2} \mathrm{O}=5 \%$; $\mathrm{CO}_{2}=33 \% ; \mathrm{CH}_{4}=62 \%$ (Bozano Gandolfi 2008), produced biogas is estimated. Similar values for biogas composition and TVS degradation efficiency can be found in other literature sources (Pognani et al. 2012; Mata-Alvarez 2003). The input and output flows for the wet AD treatment line were calculated and reported in Fig. $1,{ }^{2}$ in reference to 1 ton of entering SS-OF. The specific methane yield results about $0.260 \mathrm{Nm}^{3} / \mathrm{kg}_{\mathrm{TVS}}$ of entering SS-OF, falling within the range of values collected in the literature (Khalid et al. 2011). The produced biogas is used to co-generate EE and thermal energy (TE) in an internal combustion engine (ICE). Hence, assuming 0.35 and 0.53 for, respectively, ICE EE and TE conversion efficiencies and considering the internal consumptions of EE-equal to $60.68 \mathrm{kWh} / \mathrm{t}_{\mathrm{ss}-\mathrm{OF}}$ (Bozano Gandolfi 2008) —and TE_equal to $115.64 \mathrm{kWh} /$ $\mathrm{t}_{\mathrm{ss}-\mathrm{OF}}$ (Bozano Gandolfi 2008) - the net EE and TE productions were calculated. Also, main atmospheric emissions from ICE were considered, assuming emission factors for nitrous oxides (NOx: 4,000 kg/10 ${ }^{6} \mathrm{Nm}^{3} \mathrm{CH}_{4}$ ), particulate matter (PM: $770 \mathrm{~kg} / 10^{6} \mathrm{Nm}^{3} \mathrm{CH}_{4}$ ), and carbon monoxide (CO: $7,500 \mathrm{~kg} / 10^{6} \mathrm{Nm}^{3} \mathrm{CH}_{4}$ ) for methane combustion in ICE (US-EPA 2000).

The dehydrated digestate from the solid/liquid separation step requires an aerobic biostabilization process. Digestate is mixed with the GW amount available at each plant-according to Table 1-and the mixture is aerobically stabilized. For this process, the same assumptions previously reported for composting in paragraph "Scenario 1 " are used. Compost obtained from aerobic biostabilization of digestate and $\mathrm{GW}$ is used in agriculture. The

\footnotetext{
2 Additional assumptions: TS in wastewater: $0.79 \%$; TS in digestate after solid/liquid separation: $27 \%$; fresh water make-up: $17.73 \%$ of mass flow exiting from the pulper (Bozano Gandolfi 2008); flocculants consumption: $0.026 \%$ of mass flow exiting from digester (Bozano Gandolfi 2008).
}

beneficial effects were calculated as previously explained, according to Hermann et al. (2011).

The treatments of the wastewater produced in the AD (from solid/liquid separation process as shown in Fig. 1) and of leachate produced in the aerobic biostabilization posttreatment are accounted for, according to the methods and assumptions reported in the previous paragraph "Wastewater/leachate treatment."

The inventory for Scenario 2 is summarized in Table 3.

\section{Scenario 3}

Scenario 3 is built around the hypothesis of realizing only three AD plants, located upstream of three of the six existing aerobic composting plants, each of them located in one of the three provinces (Arezzo, Siena, and Grosseto) belonging to the south Tuscany territory. The AD plants are located upstream of the existing aerobic biostabilization plants A, C, and E. Hence, 20,854 t/year of SS-OF are transported from plant B to plant A (distance $32 \mathrm{~km}$ ), $10,002 \mathrm{t}$ /year of SS-OF are transported from plant D to plant C (distance $60 \mathrm{~km}$ ), and 15,369 t/year of SS-OF are transported from plant $\mathrm{F}$ to plant $\mathrm{E}$ (distance $80 \mathrm{~km}$ ). The digestate is aerobically biostabilized in the local plant with the available GW. The other existing aerobic biostabilization plants-without an upstream digester-proceed to only GW composting. Compost obtained from aerobic biostabilization of digestate and GW is used in agriculture. The beneficial effects were calculated as previously explained, according to Hermann et al. (2011).

All the processes were modeled as for Scenario 2. The only difference between Scenarios 2 and 3 lays in the SSOF transport requirements.

Fuel consumption and pollutant emissions from transport were estimated according to methodology reported in EMEP/EEA air pollutant emission inventory guidebook (EEA 2009), considering a heavy duty vehicle with 14-20 t capacity, fueled by diesel, Euro III, at $60 \mathrm{~km} / \mathrm{h}$ average speed.

The inventory for Scenario 3 is summarized in Table 3.

\section{Scenario 4}

Scenario 4 is built around the hypothesis of using existing anaerobic digesters serving WWTPs, in order to realize the co-digestion of SS-OF and WWTP sludge, according to the available plants and sludge production previously reported in Table 1.

The SS-OF requires to be pretreated before being mixed with the WWTP sludge. A wet pretreatment process-as described in a previous work (Lombardi et al. 2009)—was assumed for the separation of the undesired components from the SS-OF compositions. About $12.61 \%$ of the 
Fig. 1 Input and output material and energy flows of the wet $\mathrm{AD}$ treatment line, for 1 ton of entering SS-OF

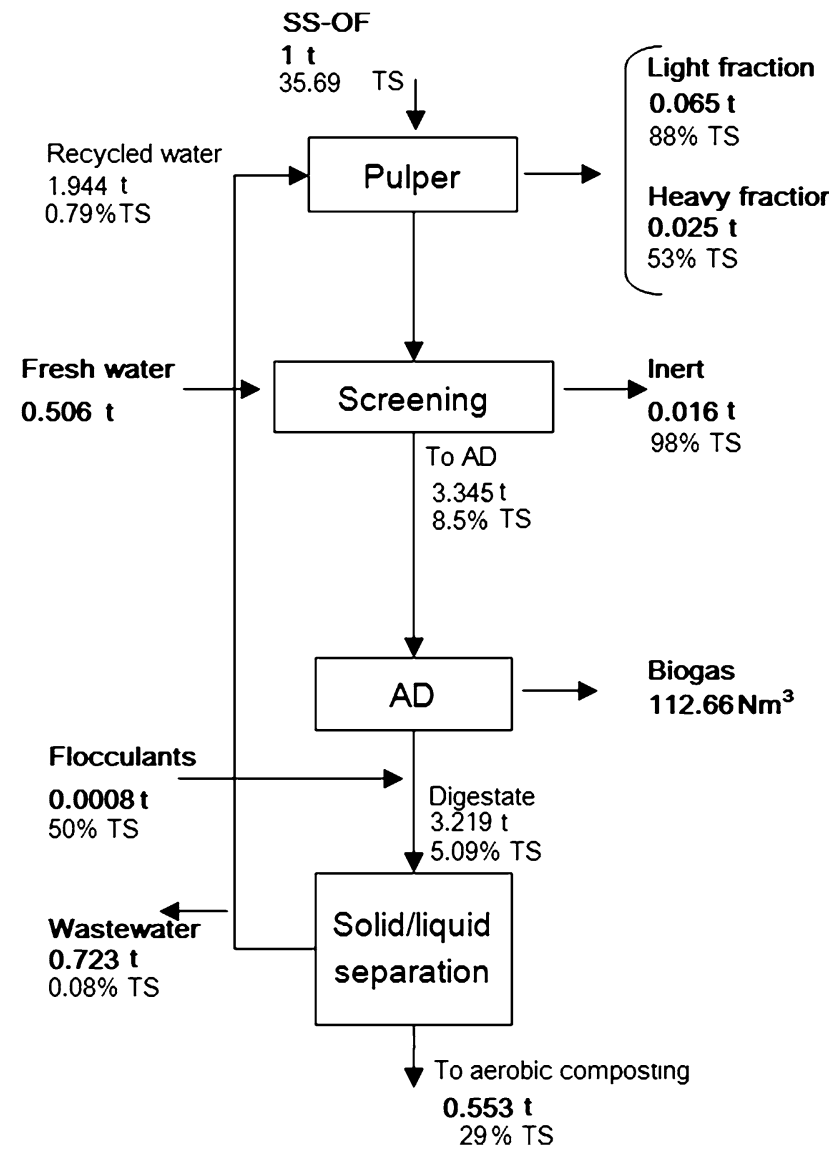

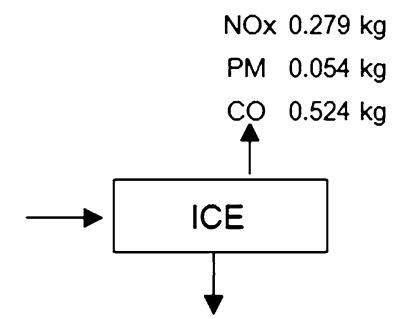

Gross Electric Energy $233 \mathrm{kWh}$ Gross Thermal Energy 353 kWh

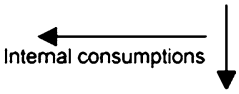

Net Electric Energy $172 \mathrm{kWh}$ Net Thermal Energy $237 \mathrm{kWh}$ entering SS-OF is sorted out, while the organic remaining part is mixed with the sludge. The TS and TVS contents of the remaining part are those reported in Table 2 for the kitchen waste.

TS $(1.7 \%)$ and TVS (68 \% of TS) contents for WWTP sludge were assumed from the literature (Metcalf and Eddy 1991; Vesilind 2003; Bolzonella et al. 2006).

Then, it was assumed to produce a mixed substrate with an overall TS content of about $5 \%$ (Lombardi et al. 2009), which is a value similar to that used by Bolzonella et al. (2006)_equal to 4,1\%-in the co-digestion process operated at the Treviso plant. The desired substrate can be obtained mixing 11-12\% w/w of remaining organic fraction and 89-88 \% w/w of WWTP sludge. The amounts of SS-OF consequently acceptable by each WWTP digester are 9,430 t/year in WWTP1; 5,810 t/year in WWTP2; and 4,957 t/year in WWTP3.

Considering the TVS degradation efficiency equal to $59.24 \%$ (Lombardi et al. 2009), the biogas production was estimated, assuming the following volumetric composition: $\mathrm{H}_{2}=0 \% ; \quad \mathrm{H}_{2} \mathrm{O}=5.48 \% ; \quad \mathrm{CO}_{2}=43.30 \%$; $\mathrm{CH}_{4}=51.22 \%$ (Lombardi et al. 2009). The calculated specific gas production resulted in about $0.48 \mathrm{Nm}^{3} / \mathrm{kg}_{\mathrm{TVS}}$, equal to $0.246 \mathrm{Nm}_{\mathrm{CH} 4}^{3} / \mathrm{kg}_{\mathrm{TVS}}$. These values are comparable with those obtained by Bolzonella et al. (2006), in similar conditions of co-digestion of sludge and organic fraction of MSW in the Treviso plant, that are $0.43 \mathrm{Nm}^{3} / \mathrm{kg}_{\mathrm{TVS}}$ as specific gas production, with $64 \%$ volumetric concentration of methane, which results in about $0.275 \mathrm{Nm}_{\mathrm{CH} 4}^{3} / \mathrm{kg}_{\mathrm{TVS}}$.

Electric energy consumption-mainly for the SS-OF pretreatment and digestate dehydration-was assumed to be $17.96 \mathrm{kWh}$ per $\mathrm{m}^{3}$ of digester feeding stream (Lombardi et al. 2009), and the thermal energy consumption-mainly for digester heating — was assumed to be $43.06 \mathrm{kWh}$ per $\mathrm{m}^{3}$ of digester feeding stream (Lombardi et al. 2009). Both assumed electric and thermal energy consumption values will be considered as changing parameters in the result sensitivity analysis, in particular increasing and decreasing each specific consumption value of $\pm 25 \%$.

Also, in this case, it was assumed to use the produced biogas in ICE in order to co-generate EE (conversion efficiency 0.35 ) and thermal energy (conversion efficiency 0.53). Also, main atmospheric emissions from ICE were considered, assuming emission factors for methane combustion in ICE (US-EPA 2000). Assuming that the digestate (which has approximately $3 \%$ of calculated TS content) is dehydrated up to $30 \%$ TS content, the amount 
of dehydrated digestate to be sent to aerobic biostabilization was calculated. The separated wastewater is processed according to paragraph "Wastewater/leachate treatment."

The overall amount of SS-OF acceptable in co-digestion $(20,198 \mathrm{t} /$ year $)$ is far less than the overall produced amount $(105,399$ t/year). For this reason, in Scenario 4, it was assumed that part of the SS-OF is still processed in devoted AD plants, as in Scenario 2, while part is transported to the WWTP. In particular, 9,430 t/year of SS-OF ${ }^{3}$ are transported from plant A to plant WWTP1 (distance $3 \mathrm{~km}$ ); $5,810 \mathrm{t} / \mathrm{y}$ of SS-OF are transported from plant $\mathrm{C}$ to plant WWTP2 (distance $68 \mathrm{~km}$ ); 4,957 t/year of SS-OF are transported from plant $\mathrm{F}$ to plant WWTP3 (distance $43 \mathrm{~km})$.

The digestate flows from co-digestion plants are returned to the existing aerobic biostabilization plants (from plant WWTP1 to plant B, $35 \mathrm{~km}$; from WWTP2 to plant C, $68 \mathrm{~km}$; from WWTP3 to plant F, $43 \mathrm{~km}$ ), and they are composted together with the local digestate and GW. Compost obtained from aerobic biostabilization of digestate (from SS-OF digestion and from SS-OF co-digestion with WWTP sludge) and GW is used in agriculture. The beneficial effects were calculated as previously explained, according to Hermann et al. (2011). Of course the quality of the compost obtained from digestate produced by codigestion of SS-OF with WWTP sludge is expected to be slightly different from that of compost obtained only from SS-OF or SS-OF digestate, since the sludge is richer in heavy metals (Smith 2009; Hospido et al. 2005). However, independently from the aerobically biostabilized substrate, the produced compost must respect national law limits-in reference to Italian situation-in heavy metals and other substances contents to be effectively used in agriculture; thus, the potential addiction of such substances to the soil is expected to be similar, even for the compost obtained from the digestate produced by the co-digestion of SS-OF and WWTP sludge.

Fuel consumption and pollutant emissions from transport were estimated according to EMEP/EEA methodology (EEA 2009), considering a heavy duty vehicle with 14-20 t capacity, fueled by diesel, Euro III, at $60 \mathrm{~km} / \mathrm{h}$ average speed

The inventory for Scenario 4 is summarized in Table 3, distinguishing the contributions from the $\mathrm{AD}$ treatment lines and from the CO-AD treatment lines.

In order to make comparable the Scenario 4 with the others, it is necessary to take into account that in this scenario, an additional input is considered, which is the overall amount of WWTP sludge. Such an input is not present in the other scenarios, and consequently, the

\footnotetext{
3 This is the overall amount of SS-OF of plant A, so in this scenario, plant A performs only aerobic composting of GW.
}

Table 4 Inventory table for avoided processes due to WWTP sludge conventional digestion

\begin{tabular}{ll}
\hline Input & \\
Sludge [t/year] & $136-385$ \\
Methanol consumption [t/year] & 77 \\
EE for AD process [kWh/year] & $636-548$ \\
EE for wastewater treatment [kWh/year] & $464-618$ \\
EE total consumption [kWh/year] & $1-101-166$ \\
ET for AD process [kWh/year] & $1-535-138$ \\
Fuel [kg/year] & \\
Output & \\
Sludge from wastewater treatment [t of dry matter/y] & 636 \\
$\mathrm{NOx}$ emission to air [kg/year] & $1-638$ \\
PM emission to air [kg/year] & 315 \\
$\mathrm{CO}$ emission to air [kg/year] & $3-072$ \\
Emissions from transport & \\
$\mathrm{CO}$ emission to air [kg/year] & 20 \\
$\mathrm{VOC}$ emission to air [kg/year] & 4 \\
$\mathrm{CH}{ }_{4}$ emission to air [kg/year] & 1 \\
$\mathrm{NMVOC} \mathrm{emission} \mathrm{to} \mathrm{air} \mathrm{[kg/year]}$ & 3 \\
$\mathrm{NOx}$ emission to air [kg/year] & 70 \\
$\mathrm{PM}$ emission to air [kg/year] & 2 \\
$\mathrm{SOx}$ emission to air [kg/year] & 2 \\
$\mathrm{CO}_{2}$ emission to air [kg/year] & 10,498 \\
\hline
\end{tabular}

comparability would be missing. To avoid such a problem, the conventional treatment of the WWTP sludge was considered as an avoided effect for Scenario 4, subtracting the environmental impacts due to this treatment (which is equivalent to adding the WWTP sludge effect to the other three scenarios).

Conventional WWTP sludge treatment was modeled assuming that the sludge-according to the amounts in Table $1-$ is thickened to $5 \%$ TS and digested with an assumed TVS removal efficiency of $34 \%$, producing the biogas with $61 \%$ volumetric of $\mathrm{CH}_{4}$ (Cavinato et al. 2013). The obtained specific gas production resulted in about 0.29 $\mathrm{Nm}^{3} / \mathrm{kg}_{\text {TVS }}$, comparable with the value obtained by Bolzonella et al. (2006) equal to $0.26 \mathrm{Nm}^{3} / \mathrm{kg}_{\mathrm{TVS}}$, in the digestion of only sludge in the Treviso plant.

Biogas combustion in ICE produces $\mathrm{EE}$ and TE according to the previously assumed conversion efficiencies. AD processes internal consumptions of electric and thermal energy - assumed, respectively, equal to 43.8 and $78.6 \mathrm{kWh} / \mathrm{t}$ per ton of sludge with $5 \% \mathrm{TS}$, in the case of only sludge digestion (Lombardi et al. 2009) - are larger than the produced EE and TE. As a matter of fact, the $\mathrm{AD}$ of only WWTP requires external input of energy, while when co-digestion is applied, such consumptions are supplied by biogas extra production. The beneficial effect of saving those consumptions is hence considered. 
Both assumed electric and thermal energy consumption values will be considered as changing parameters in the result sensitivity analysis, in particular increasing and decreasing each specific consumption value of $\pm 25 \%$.

Also, the WWTP sludge digestate is dehydrated up to $30 \%$ TS, and the resulting waste water is processed according to the assumptions in paragraph "Wastewater/ leachate treatment." Table 4 summarizes the inventory for the above-cited processes. The environmental impacts due to this inventory will be accounted with a negative sign (avoided effects).

Electric and thermal energy net production from biogas was considered as a beneficial effect and, hence, as avoided production from conventional energy sources. Ecoinvent database in SimaPro (PRé 2012) was used to make the inventory of both electric and thermal energy, considering, respectively, the Italian electric mix and the thermal energy produced from natural gas combustion in boiler.

Also, for water, diesel, methanol, and flocculants consumptions, inventory was retrieved from ecoinvent database in SimaPro (PRé 2012).

\section{Results and discussion}

Results are presented according to life cycle impact assessment, which examines the mass and energy inventory input and output data for a product system to translate these data to better identify their possible environmental relevance and significance. This translation uses, where possible, numerical indicators for specific subjects or categories that reflect in some manner the system environmental loading or resources depletion for that category. These indicators then constitute an environmental loading and resources depletion profile for a system. This profile with possible further analysis and weighting is intended to provide an additional useful perspective on the possible environmental significance in one or more general areas of resources, natural environment, and human health.

In this study, environmental indicators according to the Eco-indicator'95 method have been used (Goedkoop 1995). Ecoindicator' 95 method uses nine environmental effect indicators (greenhouse effect: GHE; ozone depletion: OD; acidification: A; eutrophication: E; heavy metals: HM; carcinogens: C; winter smog: WS; summer smog: SS; pesticides: P). Two additional indicators were added: primary energy consumption (PE), calculated as the sum of low heating value of energy sources in the inventory; and $\mathrm{SW}$, calculated as the sum of amount of SW in the inventory, disregarding their types.

The Ecoindicator'95 effects can be normalized and weighted to obtain a single indicator score in eco-point (Goedkoop 1995). Such normalization and weighting steps were not performed in this study.

\section{Impact assessment}

Table 5 shows the impact assessment results in terms of characterization values, using for each indicator the proper unit (Goedkoop 1995), in reference to the scenarios previously defined.

Impact assessment indicators related to digestion and co-digestion scenarios ( $n .2,3$, and 4) have in general negative values, while aerobic stabilization scenario $(n .1)$ ones have positive values, except for GHE, due to the avoided effect of the use of compost. As a matter of fact, the introduction of $\mathrm{AD}$ allows for energy and emissions savings through the electric and thermal net energy production. This leads to avoided effects and hence negative values of the indicators, meaning improvements in the environmental performances. These results are in agreement with other LCA studies in which composting and AD associated with EE and ET production are compared, highlighting better performances of AD-based scenarios

Table 5 Impact assessment results. Characterization values

\begin{tabular}{|c|c|c|c|c|c|c|}
\hline & Scenario 1 & Scenario 2 & Scenario 3 & Scenario 4 & Scenario $4+25 \%$ & Scenario $4-25 \%$ \\
\hline $\mathrm{GHE}\left[\mathrm{kgCO}_{2 \mathrm{eq}}\right]$ & $-9.95 \mathrm{E}+06$ & $-2.31 E+07$ & $-2.29 \mathrm{E}+07$ & $-2.25 \mathrm{E}+07$ & $-2.19 \mathrm{E}+07$ & $-2.31 \mathrm{E}+07$ \\
\hline OD $\left[\mathrm{kgCFC} 11_{\mathrm{eq}}\right]$ & $2.08 \mathrm{E}-01$ & $-1.52 E+00$ & $-1.10 \mathrm{E}+00$ & $-1.24 \mathrm{E}+00$ & $-1.17 \mathrm{E}+00$ & $-1.30 \mathrm{E}+00$ \\
\hline $\mathrm{A}\left[\mathrm{kgSO}_{2 \mathrm{eq}}\right]$ & $8.95 \mathrm{E}+03$ & $-3.95 E+04$ & $-3.82 \mathrm{E}+04$ & $-3.83 \mathrm{E}+04$ & $-3.64 \mathrm{E}+04$ & $-4.01 \mathrm{E}+04$ \\
\hline $\mathrm{E}\left[\mathrm{kgPO}_{4 \mathrm{eq}}\right]$ & $5.68 \mathrm{E}+02$ & $-2.27 \mathrm{E}+01$ & $1.81 \mathrm{E}+02$ & $-9.06 \mathrm{E}-01$ & $1.27 \mathrm{E}+02$ & $-1.22 \mathrm{E}+02$ \\
\hline $\mathrm{HM}\left[\mathrm{kgPb}_{\mathrm{eq}}\right]$ & $4.09 \mathrm{E}+00$ & $-3.40 E+01$ & $-3.36 \mathrm{E}+01$ & $-3.26 \mathrm{E}+01$ & $-3.13 \mathrm{E}+01$ & $-3.40 \mathrm{E}+01$ \\
\hline $\mathrm{C}\left[\mathrm{kgB}[\mathrm{a}] \mathrm{P}_{\mathrm{eq}}\right]$ & $8.69 \mathrm{E}-02$ & $-1.01 E+00$ & $-1.01 E+00$ & $-9.54 \mathrm{E}-01$ & $-9.13 \mathrm{E}-01$ & $-9.97 \mathrm{E}-01$ \\
\hline WS $\left[\mathrm{kgSO}_{2} \mathrm{eq}\right]$ & $6.61 \mathrm{E}+03$ & $-3.82 E+04$ & $-3.79 \mathrm{E}+04$ & $-3.73 \mathrm{E}+04$ & $-3.60 \mathrm{E}+04$ & $-3.85 \mathrm{E}+04$ \\
\hline $\mathrm{SS}\left[\mathrm{kgC}_{2} \mathrm{H}_{4 \mathrm{eq}}\right]$ & $2.90 \mathrm{E}+02$ & $-2.84 E+03$ & $-2.56 \mathrm{E}+03$ & $-2.54 \mathrm{E}+03$ & $-2.42 \mathrm{E}+03$ & $-2.66 \mathrm{E}+03$ \\
\hline $\mathrm{P}$ [kg active substance $]$ & $0.00 \mathrm{E}+00$ & $0.00 \mathrm{E}+00$ & $0.00 \mathrm{E}+00$ & $0.00 \mathrm{E}+00$ & $0.00 \mathrm{E}+00$ & $0.00 \mathrm{E}+00$ \\
\hline $\mathrm{PE}[\mathrm{MJ}]$ & $2.71 \mathrm{E}+07$ & $-2.74 E+08$ & $-2.70 \mathrm{E}+08$ & $-2.58 \mathrm{E}+08$ & $-2.47 \mathrm{E}+08$ & $-2.69 \mathrm{E}+08$ \\
\hline $\mathrm{SW}[\mathrm{kg}]$ & $6.26 E+06$ & $1.16 \mathrm{E}+07$ & $1.16 \mathrm{E}+07$ & $1.20 \mathrm{E}+07$ & $1.20 \mathrm{E}+07$ & $1.20 \mathrm{E}+07$ \\
\hline
\end{tabular}


with respect to compost-based ones (Bernstad and la Cour 2011; Bovea et al. 2010). Also, studies based on multicriteria method (El Hanandeh and El-Zein 2010) show that $\mathrm{AD}$ generally is a better option than composting.

All the environmental effect indicators agree in the scoring of the considered scenarios, except the SW one (values in bold in Table 5 highlight the best value for each indicator).

For the major number of indicators, hence, among the considered scenarios, the one with the best score is Scenario 2 (six AD plants upstream of each existing aerobic biostabilization plant); the second ranked one is Scenario 3, in which three $\mathrm{AD}$ plants were assumed; the third ranked is Scenario 4 in which co-digestion is applied; and the worse one is Scenario 1, as already highlighted before.

However, indicator values for scenario 2, 3, and 4 are quite similar. The differences from Scenario 2 to Scenario 3 have to be ascribed uniquely to transport impact to/from centralized plants. The differences between Scenarios 2 and 4 are due mainly to transport (of both SS-OF and digestate) and to larger amount of wastewater to be processed.

The SW indicator is the only one for which Scenario 2 has not the best result. For this indicator, the values are positive for all the four scenarios. Moreover, for this indicator, the Scenario 1 has the lowest value. This is due to the fact that the SS-OF requires more pretreatment before being fed to $\mathrm{AD}$, with respect to aerobic biostabilization; hence, larger amount of residues are produced. Contributions to the indicator come from the resulting sludge in larger amount from wastewater treatment, too. For Scenario 4, the indicator values are also slightly higher than in Scenarios 2 and 3, due to the fact that higher amount of sludge from wastewater treatment is produced.

In order to understand how each indicator value is made up, the contributions from the main sub-processes included in the inventory are reported for scenarios 2 and 4, respectively, in Figs. 2, and 3. Contributions of main sub-processes for Scenario 3 (not reported in a devoted figure for conciseness matter) are similar to those reported in Fig. 2 for Scenario 2, in general with higher percentages coming from transport of SS-OF to centralized plants.

The corresponding figure for scenario 1 was not reported, being the main contribution ( $>94 \%$ ) for each indicator given by the EE consumption for composting process. The only exceptions are the GHE indicator, where the main negative contribution is given by the avoided effects for the use of compost, and the SW indicator, which is made up by both contributions of scraps from SS-OF and wastewater treatment sludge.

In Scenario 2, all the indicators are negative (except $\mathrm{SW})$. The main avoided contributions come from the net production of electric (AD EE) and thermal energy (AD TE) from biogas. Among the positive contributions, the impacts due to ICE emissions and EE consumption for composting process (compost EE) are the most relevant.

Similarly, in Scenario 3, all the indicators are negative, with the exception of $\mathrm{E}$ (and again SW). The main avoided contributions come from the net production of electric and thermal energy from biogas. Among the positive contributions, the impacts due to ICE emissions and EE consumption for composting process are the most relevant to which the impacts derived from transport are added. It is
Fig. 2 Share contributions to environmental indicators for Scenario 2

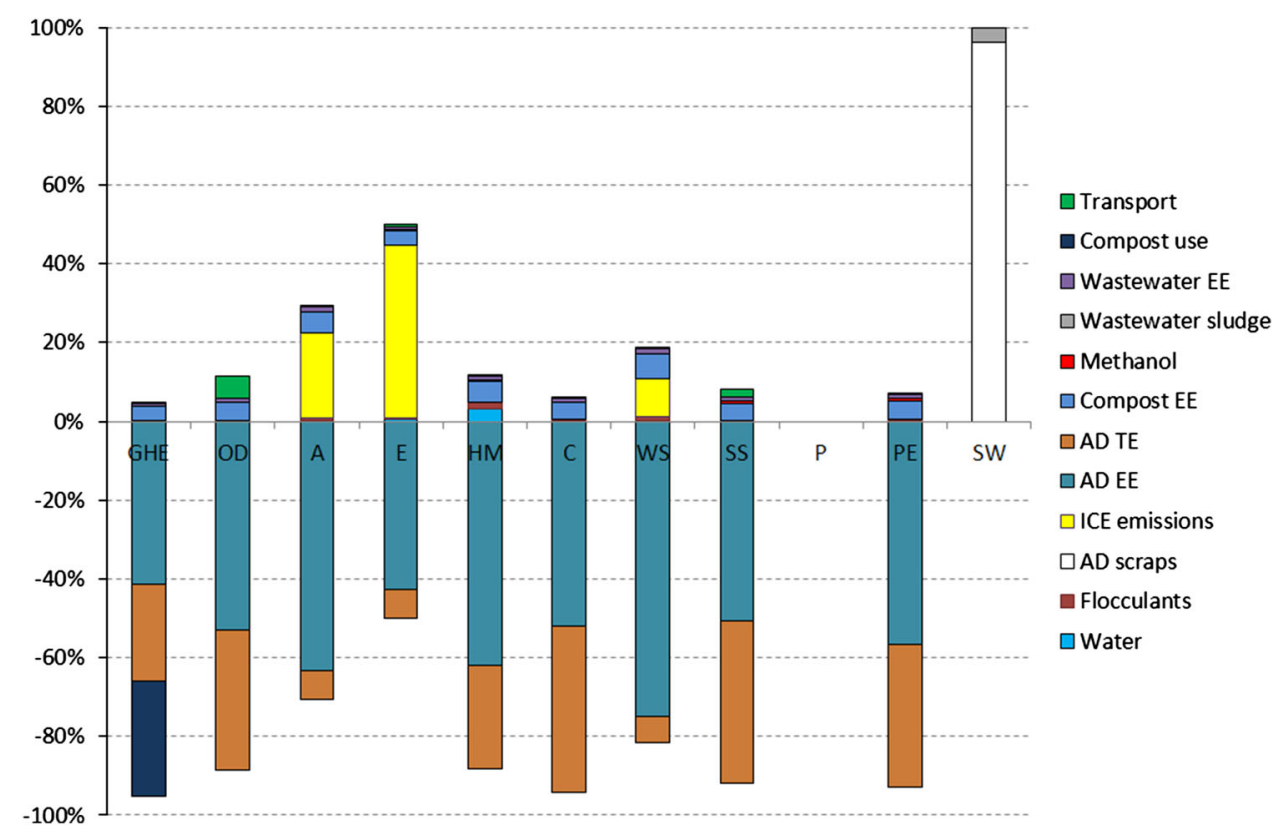


Fig. 3 Share contributions to environmental indicators for Scenario 4

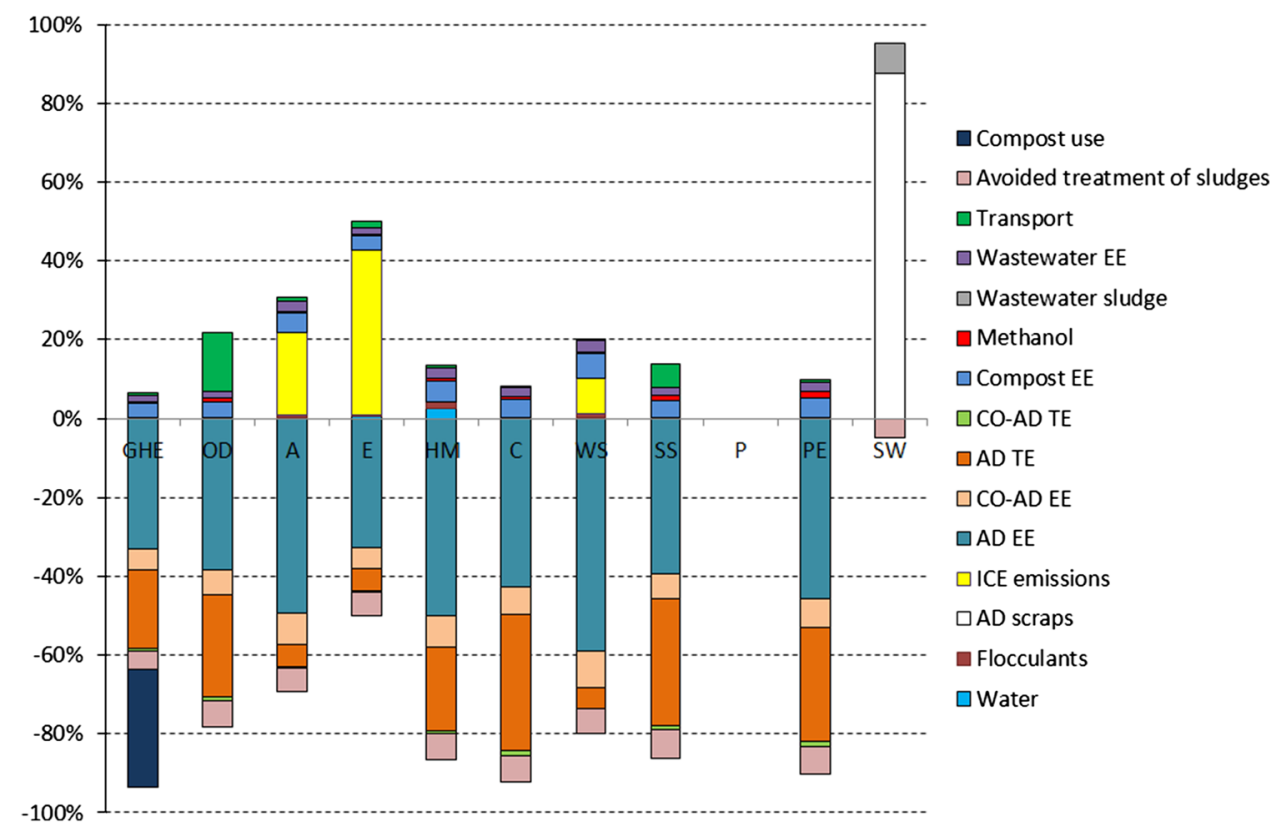

just this latter contribution that is responsible for the positive value assumed by the $\mathrm{E}$ indicator.

Concerning Scenario 4, the avoided impacts derive mainly from the electric and energy production from $\mathrm{AD}$ biogas use, while a lower contribution is given by the electric (CO-AD EE) and thermal energy (CO-AD TE) production from CO-AD biogas. This is mainly due to the fact that only about the $19 \%$ of the total SS-OF is processed in co-digestion. Moreover, the ratio of electric and thermal energy consumption for SS-OF pretreatment to the gross production is higher in Scenario 4 than in Scenarios 2-3 (Table 3).

Among the positive contributions, also in this scenario, the impacts due to ICE emissions and EE consumption for composting process are the most relevant to which the impacts derived from transport are added. However, transport contributions are lower than in Scenario 3, since the overall amount of SS-OF and digestate transported is lower than the amount of SS-OF transported in Scenario 3, with overall lower travelled distance.

For all the indicators, the avoided effects, due to the avoided conventional treatment of WWTP sludge, are quite evident and range from about 5 to $16 \%$ for the different indicators (except E).

\section{Impact assessment improvement}

Being the avoided effects from energy recovery so important for the impact assessment results, it was decided to perform a kind of sensitivity analysis of results with respect to preliminary assumptions.

The last two columns of Table 5 report the modified values of indicators calculated for Scenario 4 in the case of increasing and decreasing of $\pm 25 \%$ the values initially assumed for the electric and thermal energy consumptions related to co-digestion and only sludge digestion processes. Actually, the indicators change by a maximum of $\pm 5 \%$ with respect to the base case of Scenario 4, with the exception of $\mathrm{E}$, that in the case of $25 \%$, increase becomes positive. The overall ranking of the scenarios does not change. However, some changes happen in the comparison between scenarios 3 and 4 . When the consumptions are increased by $25 \%$, A and E of Scenario 4 assume a worse value than in Scenario 3; when the consumptions are decreased by $25 \%$, HM and WS become better in Scenario 4 , with respect to Scenario 3 .

Then, the attention was focused on thermal energy effective use and EE consumption for SS-OF pretreatment in Scenarios 2, 3, and 4.

First of all, the impact assessment calculation was updated eliminating the net thermal energy availability, considering that thermal energy is produced just to supply the internal digestion consumptions, but no net thermal energy is sold out of the plant (Modification 1). This assumption is also linked to the fact that in general-at least in Italy - the heat use is less common in this kind of plant, mainly due to the distance at which waste treatment plants generally are from potential heat users. Also, engines fueled with biogas benefit of incentives for electricity production (such as Green Certificates in Italy) for plants based on renewables, making the operation of these units a viable solution even if no heat is usefully recovered (Vaja and Gambarotta 2010).

Updated results are reported in Table 6, in which the best value for each indicator is highlighted in bold. As a matter of fact, the differences among the values for 
Table 6 ImprovementImpact assessment results

\begin{tabular}{|c|c|c|c|c|}
\hline & Scenario 1 & Scenario 2 & Scenario 3 & Scenario 4 \\
\hline \multicolumn{5}{|c|}{ Modification 1-disregarding net thermal energy production for Scenario 2, 3 and 4} \\
\hline $\mathrm{GHE}\left[\mathrm{kgCO}_{2 \mathrm{eq}}\right]$ & $-9.95 \mathrm{E}+06$ & $-1.68 \mathrm{E}+07$ & $-1.65 \mathrm{E}+07$ & $-1.72 \mathrm{E}+07$ \\
\hline $\mathrm{OD}\left[\mathrm{kgCFC} 11_{\mathrm{eq}}\right]$ & $2.08 \mathrm{E}-01$ & $-8.16 \mathrm{E}-01$ & $-3.98 \mathrm{E}-01$ & $-6.47 \mathrm{E}-01$ \\
\hline $\mathrm{A}\left[\mathrm{kgSO}_{2 \mathrm{eq}}\right]$ & $8.95 \mathrm{E}+03$ & $-3.26 \mathrm{E}+04$ & $-3.13 \mathrm{E}+04$ & $-3.25 \mathrm{E}+04$ \\
\hline $\mathrm{E}\left[\mathrm{kgPO}_{4 \mathrm{eq}}\right]$ & $5.68 \mathrm{E}+02$ & $6.33 \mathrm{E}+02$ & $8.37 \mathrm{E}+02$ & $5.48 \mathrm{E}+02$ \\
\hline $\mathrm{HM}\left[\mathrm{kgPb}_{\mathrm{eq}}\right]$ & $4.09 \mathrm{E}+00$ & $-2.23 \mathrm{E}+01$ & $-2.19 \mathrm{E}+01$ & $-2.28 E+01$ \\
\hline $\mathrm{C}\left[\mathrm{kgB}[\mathrm{a}] \mathrm{P}_{\mathrm{eq}}\right]$ & $8.69 \mathrm{E}-02$ & $-5.28 \mathrm{E}-01$ & $-5.27 \mathrm{E}-01$ & $-5.48 \mathrm{E}-01$ \\
\hline $\mathrm{WS}\left[\mathrm{kgSO}_{2} \mathrm{eq}\right]$ & $6.61 \mathrm{E}+03$ & $-3.42 E+04$ & $-3.40 \mathrm{E}+04$ & $-3.40 \mathrm{E}+04$ \\
\hline $\mathrm{SS}\left[\mathrm{kgC}_{2} \mathrm{H}_{4 \mathrm{eq}}\right]$ & $2.90 \mathrm{E}+02$ & $-1.44 \mathrm{E}+03$ & $-1.16 \mathrm{E}+03$ & $-1.37 \mathrm{E}+03$ \\
\hline $\mathrm{P}[\mathrm{kg}$ active substance $]$ & $0.00 \mathrm{E}+00$ & $0.00 \mathrm{E}+00$ & $0.00 \mathrm{E}+00$ & $0.00 \mathrm{E}+00$ \\
\hline $\mathrm{PE}[\mathrm{MJ}]$ & $2.71 \mathrm{E}+07$ & $-1.58 \mathrm{E}+08$ & $-1.55 \mathrm{E}+08$ & $-1.61 E+08$ \\
\hline $\mathrm{SW}[\mathrm{kg}]$ & $6.26 E+06$ & $1.16 \mathrm{E}+07$ & $1.16 \mathrm{E}+07$ & $1.20 \mathrm{E}+07$ \\
\hline \multicolumn{5}{|c|}{ Modification 2-increasing anaerobic digestion electric consumption for Scenarios 2, 3, and 4} \\
\hline $\mathrm{GHE}\left[\mathrm{kgCO}_{2 \mathrm{eq}}\right]$ & $-9.95 \mathrm{E}+06$ & $-2.12 E+07$ & $-2.10 \mathrm{E}+07$ & $-2.10 \mathrm{E}+07$ \\
\hline $\mathrm{OD}\left[\mathrm{kgCFC} 11_{\mathrm{eq}}\right]$ & $2.08 \mathrm{E}-01$ & $-1.34 \mathrm{E}+00$ & $-9.18 \mathrm{E}-01$ & $-1.09 \mathrm{E}+00$ \\
\hline $\mathrm{A}\left[\mathrm{kgSO}_{2 \mathrm{eq}}\right]$ & $8.95 \mathrm{E}+03$ & $-2.88 \mathrm{E}+04$ & $-2.76 \mathrm{E}+04$ & $-2.97 \mathrm{E}+04$ \\
\hline $\mathrm{E}\left[\mathrm{kgPO}_{4 \mathrm{eq}}\right]$ & $5.68 \mathrm{E}+02$ & $6.31 \mathrm{E}+02$ & $8.35 \mathrm{E}+02$ & $5.28 \mathrm{E}+02$ \\
\hline $\mathrm{HM}\left[\mathrm{kgPb}_{\mathrm{eq}}\right]$ & $4.09 \mathrm{E}+00$ & $-2.92 \mathrm{E}+01$ & $-2.88 \mathrm{E}+01$ & $-2.87 \mathrm{E}+01$ \\
\hline $\mathrm{C}\left[\mathrm{kgB}[\mathrm{a}] \mathrm{P}_{\mathrm{eq}}\right]$ & $8.69 \mathrm{E}-02$ & $-9.08 E-01$ & $-9.07 \mathrm{E}-01$ & $-8.69 \mathrm{E}-01$ \\
\hline WS $\left[\mathrm{kgSO}_{2} \mathrm{eq}\right]$ & $6.61 \mathrm{E}+03$ & $-3.02 \mathrm{E}+04$ & $-2.99 \mathrm{E}+04$ & $-3.09 E+04$ \\
\hline SS $\left[\mathrm{kgC}_{2} \mathrm{H}_{4 \mathrm{eq}}\right]$ & $2.90 \mathrm{E}+02$ & $-2.53 E+03$ & $-2.25 \mathrm{E}+03$ & $-2.29 \mathrm{E}+03$ \\
\hline $\mathrm{P}$ [kg active substance $]$ & $0.00 \mathrm{E}+00$ & $0.00 \mathrm{E}+00$ & $0.00 \mathrm{E}+00$ & $0.00 \mathrm{E}+00$ \\
\hline $\mathrm{PE}[\mathrm{MJ}]$ & $2.71 \mathrm{E}+07$ & $-2.42 \mathrm{E}+08$ & $-2.39 \mathrm{E}+08$ & $-2.32 \mathrm{E}+08$ \\
\hline $\mathrm{SW}[\mathrm{kg}]$ & $6.26 E+06$ & $1.16 \mathrm{E}+07$ & $1.16 \mathrm{E}+07$ & $1.20 \mathrm{E}+07$ \\
\hline
\end{tabular}

Scenarios 2, 3, and 4 for each indicator are reduced. In particular, it happens that Scenario 4 becomes better than Scenario 2 for several indicators as GHE, E, HM, C, and $\mathrm{PE}$. The results are linked to the fact that in general in Scenario 4, the net thermal energy is about $20 \%$ less that in Scenarios 2 and 3 (Table 3), so disregarding such a contribution is less sensitive for Scenario 4 than for the other two.

According to the modified assumptions, Scenario 4 collects the major number of lowest indicators (five indicators out of ten, excluding $\mathrm{P}$ which is always absent).

The second modification (Modification 2) to original assumptions is related to the internal consumption of EE for the SS-OF pretreatments prior to being fed to AD process. Such consumption was originally assumed equal to $60.68 \mathrm{kWh} / \mathrm{t}_{\mathrm{SS}-\mathrm{OF}}$. In this analysis, the consumption value was increased by $50 \%$, becoming about $91 \mathrm{kWh} / \mathrm{t}_{\mathrm{SS}-\mathrm{OF}}$. An increase in the internal consumption value means a decrease in the net EE and, finally, a reduced avoided effect. The environmental indicators are modified as reported in Table 6. The indicators for Scenarios 2, 3, and 4 are in general worse than in the reference case. Scenario 2 is no more indicated as the best choice for all the indicators, but only for six out of ten (GHE, OD, HM, C, SS, and PE). For the other indicators, the best values belong to Scenario 4 (A, N, and WS), while no change results for SW.

However, in both the modified comparisons, the scenarios based on the AD of SS-OF still perform better that the one based on composting.

\section{Conclusion}

The possibility of applying AD process of the SS-OF in the south of Tuscany territory was evaluated. With respect to a reference scenario, in which the overall amount of SS-OF and GW-expected in 2013 - is addressed to aerobic biostabilization process (Scenario 1), three alternative scenarios were proposed, modeled, and compared by LCA. The first one is based on realizing one AD plant upstream of each already existing aerobic plant (Scenario 2). The second one is based on realizing only three centralized anaerobic plants (Scenario 3). The third alternative is based on co-digestion of a part of the SS-OF with sludge from WWTPs in existing sludge AD plants; the remaining part of SS-OF is processed in devoted AD plants upstream of each already existing aerobic plant (Scenario 4).

LCA impact assessment results show that AD application is always favorable with respect to the reference 
scenario in which organic wastes are aerobically processed. $\mathrm{AD}$ allows for net production of thermal and electric energy, generating negative impacts due to avoided emissions and avoided resource consumptions.

Among the compared alternatives of $\mathrm{AD}$ application, the scenario based on decentralized plants (one anaerobic plant upstream of each existing aerobic plant) resulted to be the most favorable, collecting the best value for all the considered environmental indicators, except the solid waste one. This indicator is higher for AD scenarios, because a deeper separation of undesired material from sourceselected organic fraction is required for feeding the process with respect to aerobic biostabilization; thus, a larger amount of scraps is produced. Also, being the considering anaerobic process a wet one, wastewaters is produced and sludge from the wastewater treatment is generated, contributing to the solid waste indicator.

Scenario 3, based on three centralized AD plants, resulted to be the second scored one after Scenario 2. The values for the considered indicators are in general less favorable than Scenario 2, but better than Scenario 4 (with the exception of ozone depletion, acidification, and eutrophication). However, indicator values are very close to those of Scenario 2, being the difference due only to the additional transport for moving the SS-OF from the local plant to the centralized one. Indicators increase in a range from 0.1 to $10 \%$ moving from Scenario 2 to Scenario 3 (except ozone depletion and eutrophication). The choice between decentralized and centralized anaerobic plant strategy should be evaluated also from an economic point of view, which was not the object of this study. In fact in this study, it was not checked whether the decentralized anaerobic plant sizes were above the lower limits for the economic sustainability, which could represent a strong constraint in planning the proper plant system.

Scenario 4, based on the possibility of co-digesting about $19 \%$ of the total amount of SS-OF, is quite similar to Scenario 2, because the remaining part is still processed in decentralized anaerobic plant located upstream of the existing aerobic ones. Advantages of co-digestion process are highlighted by the negative impacts due to the avoided conventional treatment of the wastewater treatment sludge which are used as co-substrate with the SS-OF. In particular, co-digestion increases the biogas production, with respect to only sludge case, allowing for covering the energy internal consumptions, avoiding the use of conventional resources for such consumptions, and also generating a net energy production and, thus, avoided effects. Nevertheless, the net energy production in co-digestion scenario is lower than in traditional $\mathrm{AD}$ ones. This issues, together with the additional impacts due to SS-OF and digestate transport, makes the indicator values for this scenario, in general, less favorable than for Scenarios 2 and 3.
The discussed results were found to be quite sensitive to changes in the assumptions related to energy recovery. In particular, if net thermal energy is not used, the values of calculated indicators for Scenario 2 become less favorable. This indication should guide the local planning toward the promotion of thermal energy use.

Similarly, if electric energy consumptions of SS-OF pretreatments are increased, the indicators for AD scenarios are less favorable, suggesting that accurate check of pretreatment consumptions in reference to a specific biowaste should be undertaken before choosing any specific technology.

Acknowledgments The authors wish to thank the Regione Toscana-Direzione Generale Politiche Territoriali e Ambientali for cofunding this study.

\section{References}

ANPA, ONR (2002) Il recupero di sostanza organica dai rifiuti per la produzione di ammendanti di qualità. Manuali e Linee Guida 7/2002 (in Italian). Availabe at http://www.isprambiente.gov.it/ contentfiles/00003500/3526-manuali-2002-07.pdf/view [last accessed June 2013]

Antonopoulos IS, Karagiannidis A, Tsatsarelis T, Perkoulidis G (2013) Applying waste management scenarios in the Peloponnese region in Greece: a critical analysis in the frame of life cycle assessment. Environ Sci Pollut R 20:2499-2511

ATO Toscana Sud (2008) Piano Straordinario, Area Vasta ATO7, ATO8 e ATO9, approvato il (in Italian). Available at http:// www.atotoscanasud.it/index.php?option $=$ com_content \&view= article \&id=72\&Itemid=130 [last accessed June 2013]

Bernstad A, la Cour Jansen J (2011) A life cycle approach to the management of household food waste-A Swedish case study. Waste Manage 31:1879-1896

Boldrin A, Hartling KR, Laugen M, Christensen TH (2010) Environmental inventory modelling of the use of compost and peat in growth media preparation. Resour Conserv Recy $54: 1250-1260$

Boldrin A, Andersen JK, Christensen TH (2011a) Environmental assessment of garden waste management in the Municipality of Aarhus, Denmark. Waste Manage 31:1560-1569

Boldrin A, Lund Neidel T, Damgaard A, Bhander GS, Møller J, Christensen TH (2011b) Modelling of environmental impacts from biological treatment of organic municipal waste in EASEWASTE. Waste Manage 31:619-630

Bolzonella D, Battistoni P, Susini C, Cecchi F (2006) Anaerobic codigestion of waste activated sludge and OFMSW: the experiences of Viareggio and Treviso plants (Italy). Water Sci Technol 53:203-211

Bovea MD, Ibáñez-Forés V, Gallardo A, Colomer-Mendoza FJ (2010) Environmental assessment of alternative municipal solid waste management strategies. A Spanish case study. Waste Manage 30:2383-2395

Bozano Gandolfi P (2008) Practical experiences in the production of biogas and energy from waste. Proceedings of Venice 2008. Second International Symposium on Energy from Biomass and Waste 17-20 November 2008. Venice, Italy

Cavinato C, Bolzonella D, Pavan P, Fatone F, Cecchi F (2013) Mesophilic and thermophilic anaerobic co-digestion of waste activated sludge and source sorted biowaste in pilot- and fullscale reactors. Renew Energ 55:260-265 
Chang JI, Tsai JJ, Wu KH (2006) Thermophilic composting of food waste. Bioresour Technol 97:116-122

Cleary J (2009) Life cycle assessments of municipal solid waste management systems: a comparative analysis of selected peerreviewed literature. Environ Int 35:1256-1266

De Baere L (2006) Will anaerobic digestion of solid waste survive in the future? Water Sci Technol 53:187-194

De Baere L, Mattheeuws B (2011) State of the art of anaerobic digestion of municipal solid waste in Europe. Proceedings of the International Conference on Solid Waste 2011- Moving Towards Sustainable Resource Management, Hong Kong SAR, P.R. China, 2-6 May 2011

EEA (2009) EMEP/EEA air pollutant emission inventory guidebook. Available at http://www.eea.europa.eu/publications/emep-eeaemission-inventory-guidebook-2009. [last accessed June 2013]

El Hanandeh A, El-Zein A (2010) The development and application of multi-criteria decision-making tool with consideration of uncertainty: the selection of a management strategy for the biodegradable fraction in the municipal solid waste. Bioresour Technol 101:555-561

Favoino E, Hogg D (2008) The potential role of compost in reducing greenhouse gases. Waste Manage Res 26:61-69

Goedkoop M (1995) The Eco-indicator 95, Final Report. PRé Consultants. Available at http://www.pre-sustainability.com/ content/reports [last accessed June 2013]

Hermann BG, Debeer L, De Wilde B, Blok K, Patel MK (2011) To compost or not to compost: carbon and energy footprints of biodegradable materials waste treatment. Polym Degrad Stab 96:1159-1171

Hospido A, Moreira MT, Martín M, Rigola M, Feijoo G (2005) Environmental evaluation of different treatment processes for sludge from urban wastewater treatments: anaerobic digestion versus thermal processes. Int J LCA 10:336-345

Intergovernmental Panel on Climate Change, IPCC (2006) In: Eggleston, S., Buendia, L., Miwa, K., Ngara, T., Tanabe, K. (Eds.), Biological treatment of solid waste. Guidelines for National Greenhouse Gas Inventory

ISO 14040 (2006) Environmental management-Life cycle assessment-Principles and framework

ISO 14044 (2006) Environmental Management. Life Cycle Assessment. Requirements and Guidelines

Khalid A, Arshad M, Anjum M, Mahmood T, Dawson L (2011) The anaerobic digestion of solid organic waste. Waste Manage 31:1737-1744

Kumar M, Ou YL, Lin JG (2010) Co-composting of green waste and food waste at low $\mathrm{C} / \mathrm{N}$ ratio. Waste Manage 30:602-609

Lombardi L, Corti A, Lubello C, Caffaz S (2009) Anaerobic codigestion of source selected organic fraction of municipal solid waste and wastewater treatment plant sludge. Sardinia 2009 Twelfth International Waste Management and Landfill Symposium S. Margherita di Pula, Cagliari, Italy; 5-9 October 2009. Cisa Editore (ISBN 978-88-903557-0-7)

Manfredi S, Christensen TH (2009) Environmental assessment of solid waste landfilling technologies by means of LCA-modeling. Waste Manage 29:32-43
Mata-Alvarez J (2003) Biomethanization of the organic fraction of municipal solid waste. IWA Publishing, London

Mata-Alvarez J, Maché S, Llabés P (2000) Anaerobic digestion of organic solid waste. An overview of research achievement and perspectives. Bioresour Technol 74:3-16

Metcalf and Eddy (1991) Wastewater engineering: treatment, disposal, reuse, 3rd edn. McGraw-Hill Inc, New York

Miller PA, Clesceri NL (2003) Waste Sites as Biological ReactorsCharacterization and Modeling. Lewis Publishers, London

Orhon D, Artan N (1994) Modelling of activated sludge systems. Technomic Publishing Company, Lancaster

Pognani M, Barrena R, Font X, Sánchez A (2012) A complete mass balance of a complex combined anaerobic/aerobic municipal source-separated waste treatment plant. Waste Manage 32:799-805

PRé (2012) http://www.pre-sustainability.com/content/simapro-lcasoftware. [last accessed June 2013]

Sedlak RI (1991) Phosphorus and nitrogen removal from municipal wastewater. Principles and practice, vol 2. Lewis Publishers, London

SINTAI (2011) Sistema Informativo Nazionale per la Tutela delle Acque Italiane-ISPRA. Available at http://www.sintai.sinanet. apat.it/ [last accessed June 2013]

Smith SR (2009) A critical review of the bioavailability and impacts of heavy metals in municipal solid waste composts compared to sewage sludge. Environ Int 35:142-156

Thanh NP, Matsui Y (2012) An evaluation of alternative household solid waste treatment practices using life cycle inventory assessment mode. Environ Monit Assess 184:3515-3527

Trujillo D, Font X, Sanchez A (2006) Use of Fenton reaction for the treatment of leachate from composting of different wastes. J Hazard Mater B138:201-204

Tunesi S (2011) LCA of local strategies for energy recovery from waste in England, applied to a large municipal flow. Waste Manage 3:561-571

Tyrrel SF, Seymour I, Harris JA (2008) Bioremediation of leachate from a green waste composting facility using waste-derived filter media. Bioresour Technol 99:7657-7664

US-EPA (2000) AP 42, Fifth Edition, Volume I. Chapter 3: stationary internal combustion sources. Available at http://www.epa.gov/ ttnchie1/ap42 [last accessed June 2013]

Vaja I, Gambarotta A (2010) Internal combustion engine (ICE) bottoming with organic rankine cycles (ORCs). Energy 35:1084-1093

Vesilind PA (2003) Wastewater treatment plant design. IWA Publishing, London

Zaman AU (2010) Comparative study of municipal solid waste treatment technologies using life cycle assessment method. Int J Environ Sci Tech 7:225-234

Zaman AU (2013) Life cycle assessment of pyrolysis-gasification as an emerging municipal solid waste treatment technology. Int J Environ Sci Tech. In press. doi:10.1007/s13762-013-0230-3 